\title{
EVALUASI PENATAUSAHAAN ASET TETAP PADA KANTOR DINAS OLAHRAGA DAN PEMUDA PROVINSI PAPUA
}

\author{
Adonia Abigael Aibekob ${ }^{1}$ \\ Syaikhul Falah ${ }^{2}$ \\ Arius A. Kambu ${ }^{3}$
}

\begin{abstract}
This study aims to obtain a clear picture of the effects of recording, inventorying and reporting on the administration of fixed assets at the Papua Province Sports and Youth Office. The type of data used is qualitative data and quantitative data. Primary and secondary data is the data source used. Data collection techniques are used, namely field data and library data studies. The study was conducted using quantitative descriptive data analysis techniques consisting of research instrument test, classic assumption test, and multiple regression analysis.

The results of the study show that recording, inventorying and reporting partially has a positive and significant effect on the administration of fixed assets at the Papua Province Sports and Youth Office. Recording, Inventory and Reporting simultaneously have a positive and significant effect on the administration of fixed assets at the Papua Province Sports and Youth Office. Recording is the dominant factor that has a significant effect on the administration of fixed assets at the Papua Province Sports and Youth Office.
\end{abstract}

Key Words: Recording, Inventory, Reporting, Administration of Assets

\section{PENDAHULUAN}

Barang Milik Negara/Daerah (BMN/D) merupakan unsur penting dalam penyelenggaraan pemerintahan khususnya dalam memberikan pelayanan kepada masyarakat (Agustin, 2018). Pemerintah Pusat/Daerah harus melakukan pengelolaan atas BMN/D agar dapat berguna bagi pemerintah dan masyarakat. Pengelolaan Barang Milik Negara/Daerah (BMN/D) telah dituntut untuk meningkatkan komitmen dalam pengelolaannya baik dalam rangka penatausahaan, pengamanan, penguatan, maupun pengamanan terhadap seluruh aset yang cukup besar.

Pengelolaan yang dilakukan dengan baik dan benar memiliki makna pengelolaan BMN/D harus taat asas (Sholeh \& Rochmansjah, 2010). Adapun asas-asas dalam pengelolaan BMN/D meliputi: asas fungsional, asas kepastian hukum, asas transparansi, asas keterbukaan, asas efisiensi, asas akuntabilitas, dan asas kepastian nilai.

\footnotetext{
${ }^{1}$ Alumni Magister Keuangan Daerah Universitas Cenderawasih

2 Dosen Magister Keuangan Daerah Universitas Cenderawasih

${ }^{3}$ Dosen Magister Keuangan Daerah Universitas Cenderawasih
} 
Dalam penyelenggaran pemerintahan, barang milik daerah merupakan salah satu hal penting namun dalam pelaksanaan pengelolaannya tidaklah mudah, sehingga sering kali terdapat berbagai persoalan terkait asset daerah. Hal ini terbukti dari masih banyaknya pengecualian kewajaran atas nilai aset pemerintah daerah dalam opini BPK RI atas Laporan Keuangan Pemerintah Daerah (LKPD). Berdasarkan hasil pemeriksaan BPK darisegi sistem pengendalian intern (SPI), penatausahaan dan pengamanan aset tetap barang milik negara pada 56 KL juga kurang memadai. Secara umum BPK (2015) pun menyatakan, kelemahan administrasi pemerintah terjadi pada pengelolaan akun aset tetap.

Pada Kantor Dinas Olahraga dan Pemuda Provinsi Papua penatausahaan aset tetap masih belum berjalan dengan baik. Hal ini disebabkan karena pada bagian-bagian yang berhubungan dengan aset pada Kantor Dinas Olahraga dan Pemuda Provinsi Papua masih kurang aktif dalam mencatat, menginventarisasikan, dan melaporkan aset tetap secara rutin. Pada pencatatan aset tetap yang ada pada Kantor Dinas Olahraga dan Pemuda Provinsi Papua masih terdapat aset-aset Kantor Dinas Olahraga dan Pemuda Provinsi Papua yang masih belum ada di pembukuan aset tetap kantor. Hal ini disebabkan oleh kurang aktifnya pegawai yang bertugas untuk mencatat aset tetap Kantor Dinas Olahraga dan Pemuda Provinsi Papua sehingga berdampak kepada kurang baiknya penatausahaan aset tetap pada Kantor Dinas Olahraga dan Pemuda Provinsi Papua.

Pada inventarisasi aset tetap di Kantor Dinas Olahraga dan Pemuda Provinsi Papua masih kurang lengkap. Hal ini sebabkan karena jenis dan barang yang ada pada Kantor Dinas Olahraga dan Pemuda Provinsi Papua kurang jelas jenis dan spesifikasinya, kondisi barang yang belum jelas, dan masih terdapat beberapa barang yang tidak diberi penomoran. Semua hal tersebut mengakibatkan penatausahaan aset tetap yang masih kurang lengkap pada Kantor Dinas Olahraga dan Pemuda Provinsi Papua.

Berdasarkan uraian latar belakang di atas maka rumusan masalah yang diajukan dalam penelitian ini adalah 1) apakan pencatatan, investarisasi dan pelaporan secara parsial mempunyai pengaruh terhadap penatausahaan asset tetap; 2) apakan pencatatan, investarisasi dan pelaporan secara parsial mempunyai pengaruh terhadap penatausahaan 
asset tetap; 3) Faktor manakah diantara pencatatan, inventarisasi, dan pelaporan yang lebih dominan berpengaruh signifikan terhadap penatausahaan aset tetap.

\section{LANDASAN TEORI DAN PENGEMBANGAN HIPOTESIS}

\section{LANDASAN TEORI}

\section{Penatausahaan}

Tata Usaha adalah suatu peraturan yang terdapat dalam suatu proses penyelenggaraan kerja (Wulandari, 2019). Tata Usaha juga dapat diartikan sebagai kegiatan untuk mengadakan pencatatan dan penyusunan keterangan-keterangan, sehingga keterangan-keterangan tersebut dapat digunakan secara langsung sebagai bahan informasi bagi pimpinan suatu organisasi yang bersangkutan dan juga oleh siapa saja yang membutuhkannya.

Dalam Permendagri No. 19 Tahun 2016 Pasal 1 disebutkan bahwa penatausahaan merupakan proses melakukan pembukuan, inventarisasi dan pelaporan barang milik daerah sesuai dengan ketentuan peraturan perundang-undangan. Dengan demikian apabila penatausahaan tidak sesuai dengan prosedur yang ditentukan maka akan mengakibatkan laporan asset Negara/daerah tidak sinkron dengan laporan keuangan.

\section{Evaluasi}

Menurut Suchman yang dikutip oleh Arikunto \& Jabar (2010 hal 56) evaluasi dipandang sebagai sebuah proses menentukan hasil yang telah dicapai dalam beberapa kegiatan yang direncanakan untukmendukung tercapainya tujuan. Definisi lain seperti dikemukakan oleh Stutflebeam yang dikutip oleh Arikunto \& Jabar (2010 hal. 57), menyatakan bahwa evaluasi merupakan proses penggambaran, pencarian danpemberian informasi yang sangat bermanfaat bagi pengambil keputusandalam menentukan alternatif keputusan.

\section{PENGEMBANGAN HIPOTESIS}

H1 : Pencatatan, inventarisasi, dan pelaporan secara parsial mempunyai pengaruh signifikan terhadap penatausahaan aset tetap pada Kantor Dinas Olahraga dan Pemuda Provinsi Papua. 
H2 : Pencatatan, inventarisasi, dan pelaporan secara simultan mempunyai pengaruh signifikan terhadap penatausahaan aset tetap pada Kantor Dinas Olahraga dan Pemuda Provinsi Papua.

H3 : Pelaporan yang lebih dominan berpengaruh signifikan terhadap penatausahaan aset tetap pada Kantor Dinas Olahraga dan Pemuda Provinsi Papua.

\section{MODEL PENELITIAN}

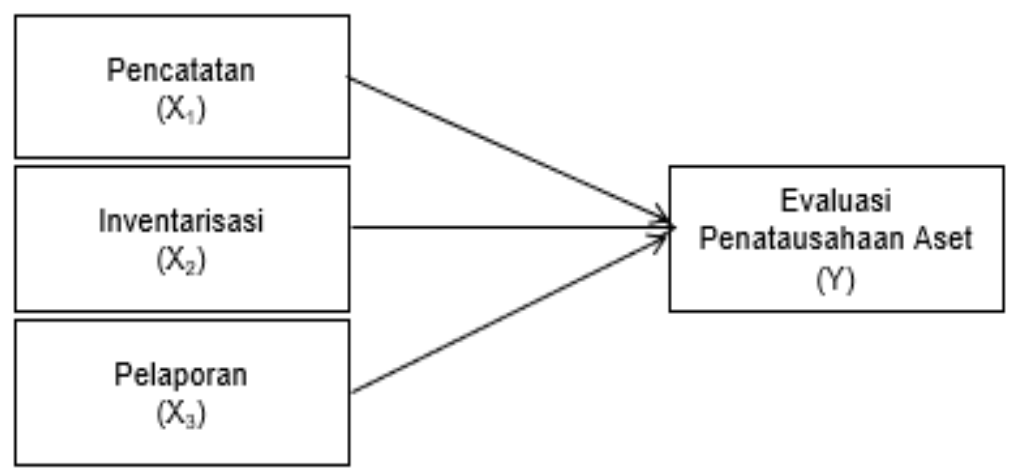

Sumber: Permendagri 19 tahun 2016

\section{METODE PENELITIAN}

Penelitian ini adalah penelitian deskriptif kualitatif dengan melakukan kegiatan penelitian lapangan (field research). Metode penelitian deskriptif adalah yaitu proses pemecahan masalah yang diselidiki dengan menjabarkan atau melukiskan kondisi objek penelitian pada periode penelitian berdasarkan fakta-fakta yang ada. Tujuan dari penelitian deskriptif ini adalah untuk memberi gambaran yang lebih jelas tentang situasi sosial, faktafakta, sifat-sifat serta hubungan antar fenomena yang diselidiki. (Nasution, 2000: 24).

Penelitian ini dilakukan pada kantor Dinas Olahraga dan Pemuda Provinsi Papua, dengan populasi adalah seluruh pegawai pada Kantor Dinas Olahraga dan Pemuda Provinsi Papua. Pengambilan sampel menggunakan rumus slovin, dan diperoleh jumlah sampel sebanyak 58 orang pegawai pada Sub Bagian Umum dan Perlengkapan, dan Bagian Keuangan pada Kantor Dinas Olahraga dan Pemuda Provinsi Papua. 
Sumber data dalam penelitian ini diambil dari data primer dan data sekunder, dengan Teknik pengumpulan data melalui observasi, wawancara, studi pustaka dan dokumentasi. Analisis data menggunakan program SPSS 22.

\section{HASIL PENELITIAN DAN PEMBAHASAN}

\section{Hasil Regresi Berganda}

Tabel 1

Hasil Analisis Regresi Berganda

Coefficients $^{\mathrm{a}}$

\begin{tabular}{|ll|r|r|r|r|}
\hline \multirow{2}{*}{ Model } & \multicolumn{2}{|c|}{ Unstandardized Coefficients } & Standardized Coefficients & \multirow{2}{*}{ Sig. } \\
\cline { 2 - 6 } & \multicolumn{1}{|c|}{ B } & Std. Error & Beta & -2.093 & .041 \\
(Constant) & -9.019 & 4.308 & .759 & 8.558 & .000 \\
X1 & .811 & .095 & .344 & 3.934 & .000 \\
X2 & .312 & .079 & .236 & 2.681 & .010 \\
X3 & .255 & .095 & & & \\
\hline
\end{tabular}

a. Dependent Variable: $Y$

Sumber: Data Primer Diolah 2019

Berdasarkan tabel diatas hasil analisis regresi bergandan yang dilakukan dengan bantuan program SPSS (Statistical Product and Service Solutions) diperoleh persamaan regresi sebagai berikut:

$$
Y=-9,019+0,811 X_{1}+0,312 X_{2}+0,255 X_{3}+e
$$

Berdasarkan persamaan regresi yang diperoleh dari perhitungan diatas maka dapat dijelaskan pengaruh antara variabel pencacatan $\left(X_{1}\right)$, inventarisasi $\left(X_{2}\right)$, dan pelaporan $\left(X_{3}\right)$ terhadap penatausahaan aset $(\mathrm{Y})$. Untuk lebih jelasnya adalah sebagai berikut:

a. Nilai Konstanta $=-9,019$

Nilai konstanta -9,019 menunjukkan bahwa apabila variabel pencacatan $\left(X_{1}\right)$, inventarisasi $\left(\mathrm{X}_{2}\right)$, dan pelaporan $\left(\mathrm{X}_{3}\right)$ dalam kondisi tetap atau konstan, maka penatausahaan aset $(Y)$ sebesar $-9,019$ satuan, yang berarti bahwa tanpa adanya variabel bebas yaitu pencacatan $\left(X_{1}\right)$, inventarisasi $\left(X_{2}\right)$, dan pelaporan $\left(X_{3}\right)$, maka penatausahaan aset (Y) akan tetap sebesar -9,019.

b. Nilai $b_{1}=0,811$ 
Nilai $b_{1}$ menunjukkan nilai 0,811 dan memiliki tanda koefisien regresi yang positif, hal tersebut menunjukkan adanya pengaruh searah antara variabel pencatatan $\left(\mathrm{X}_{1}\right)$ dengan variabel penatausahaan asset $(\mathrm{Y})$ yang artinya bahwa apabila terjadi peningkatan atau kenaikan pada variabel pencatatan $\left(\mathrm{X}_{1}\right)$ dengan asumsi bahwa variabel inventarisasi $\left(\mathrm{X}_{2}\right)$ dan pelaporan $\left(\mathrm{X}_{3}\right)$ dalam kondisi tetap atau konstan, maka penatausahaan aset $(\mathrm{Y})$ akan mengalami peningkatan dan sebaliknya.

c. Nilai $b_{2}=0,312$

Nilai $b_{2}$ menunjukkan nilai 0,312 dan memiliki tanda koefisien regresi yang positif, hal tersebut menunjukkan adanya pengaruh searah antara variabel inventarisasi $\left(X_{2}\right)$ dengan variabel penatausahaan aset $(\mathrm{Y})$ yang artinya bahwa apabila terjadi peningkatan atau kenaikan pada variabel inventarisasi $\left(X_{2}\right)$ dengan asumsi bahwa variabel pencatatan $\left(X_{1}\right)$ dan pelaporan $\left(\mathrm{X}_{3}\right)$ dalam kondisi tetap atau konstan, maka penatausahaan aset $(\mathrm{Y})$ akan mengalami peningkatan dan sebaliknya.

d. Nilai $b_{3}=0,255$

Nilai $b_{3}$ menunjukkan nilai 0,255 dan memiliki tanda koefisien regresi yang positif, hal tersebut menunjukkan adanya pengaruh searah antara variabel pelaporan $\left(X_{3}\right)$ dengan variabel penatausahaan aset $(\mathrm{Y})$ yang artinya bahwa apabila terjadi peningkatan atau kenaikan pada variabel pelaporan $\left(X_{3}\right)$ dengan asumsi bahwa variabel pencatatan $\left(X_{1}\right)$ dan inventarisasi $\left(\mathrm{X}_{2}\right)$ dalam kondisi tetap atau konstan, maka penatausahaan aset $(\mathrm{Y})$ akan mengalami peningkatan dan sebaliknya.

\section{Pengujian Hipotesis}

Untuk mengetahui atau menguji salah satu variabel bebas yang terdiri dari pencacatan $\left(X_{1}\right)$, inventarisasi $\left(X_{2}\right)$, dan pelaporan $\left(X_{3}\right)$ mempunyai pengaruh secara parsial atau individu terhadap variabel penatausahaan aset $(\mathrm{Y})$, maka digunakan uji t. Adapun hasil t hitung pada tabel berikut: 
Tabel 2

Uji T

\begin{tabular}{|c|c|c|c|c|}
\hline Variabel & $t_{\text {hitung }}$ & $\mathrm{T}_{\text {tabel }}$ & Sig & Keterangan \\
\hline Pencatatan $\left(\mathrm{X}_{1}\right)$ & 8,558 & 1,673 & 0,000 & Signifikan \\
\hline Inventarisasi $\left(\mathrm{X}_{2}\right)$ & 3,934 & 1,673 & 0,000 & Signifikan \\
\hline Pelaporan $\left(\mathrm{X}_{3}\right)$ & 2,681 & 1,673 & 0,010 & Signifikan \\
\hline
\end{tabular}

Sumber: Data Olahan, 2019

Berdasarkan uji t sesuai dengan hasil pengujian, maka dapat dijelaskan sebagai berikut:

\section{a. Pengaruh Pencatatan $\left(\mathrm{X}_{1}\right)$ terhadap penatausahaan aset $(\mathrm{Y})$}

Pada tabel 2 menunjukkan nilai $t_{\text {hitung }}$ untuk variabel pencatatan $\left(X_{1}\right)$ yaitu 8,558 dan nilai $t_{\text {tabel }} 1,673$. Karena nilai $t_{\text {hitung }}>t_{\text {tabel }}$ yaitu $8,558>1,673$ dan memiliki taraf signifikansi sebesar $0,000<0,05$, maka dapat disimpulkan bahwa pencatatan $\left(X_{1}\right)$ mempunyai pengaruh yang signifikan secara parsial terhadap penatausahaan asset tetap pada Kantor Dinas Olahraga dan Pemuda Provinsi Papua.

\section{b. Pengaruh inventarisasi $\left(\mathrm{X}_{2}\right)$ terhadap penatausahaan aset $(\mathrm{Y})$}

Pada tabel 2 menunjukkan nilai $t_{\text {hitung }}$ untuk variabel inventarisasi $\left(X_{2}\right)$ yaitu 3,934 dan nilai $t_{\text {tabel }} 1,673$. Karena nilai $t_{\text {hitung }}>t_{\text {tabel }}$ yaitu 3,934 $>1,673$ dan memiliki taraf signifikansi sebesar $0,000<0,05$, maka dapat disimpulkan bahwa inventarisasi $\left(\mathrm{X}_{2}\right)$ mempunyai pengaruh yang signifikan secara parsial terhadap penatausahaan asset tetap pada Kantor Dinas Olahraga dan Pemuda Provinsi Papua.

\section{c. Pengaruh pelaporan $\left(X_{3}\right)$ terhadap penatausahaan aset $(Y)$}

Pada tabel 2 menunjukkan nilai thitung untuk variabel pelaporan $\left(X_{3}\right)$ yaitu 2,681 dan nilai $t_{\text {tabel }} 1,673$. Karena nilai $t_{\text {hitung }}<t_{\text {tabel }}$ yaitu $2,681<1,673$ dan memiliki taraf signifikansi sebesar $0,007>0,05$, maka dapat disimpulkan bahwa penatausahaan aset $\left(X_{3}\right)$ mempunyai pengaruh yang signifikan secara parsial terhadap penatausahaan asset tetap pada Kantor Dinas Olahraga dan Pemuda Provinsi Papua.

Berdasarkan hasil uji t diatas menunjukkan bahwa variabel yang paling dominan berpengaruh terhadap penatausahaan asset tetap pada Kantor Dinas Olahraga dan Pemuda Provinsi Papua adalah variabel pencatatan $\left(X_{1}\right)$ karena memiliki nilai $t_{\text {hitung }}$ yang lebih besar 
dibandingkan dengan nilai $t_{\text {hitung }}$ variabel inventarisasi dan pelaporan yaitu sebesar 8,558 dengan nilai signifikansi sebesar 0,000.

\section{Uji F}

Pembuktian hipotesis dalam penelitian ini dilakukan dengan menggunakan Uji $\mathrm{F}$ untuk menguji pengaruh secara simultan atau bersama-sama yaitu pengaruh variabel bebas yang terdiri dari pencatatan $\left(X_{1}\right)$, inventarisasi $\left(X_{2}\right)$, dan pelaporan $\left(X_{3}\right)$ secara bersamasama (simultan) terhadap variabel penatausahaan aset (Y), maka digunakan uji F. Adapun nilai $F_{\text {hitung }}$ sebagai berikut:

Tabel 3

Uji F

\begin{tabular}{|c|c|c|c|c|c|c|}
\hline \multicolumn{7}{|c|}{ ANOVA $^{a}$} \\
\hline \multicolumn{2}{|l|}{ Model } & $\begin{array}{l}\text { Sum of } \\
\text { Squares }\end{array}$ & Df & $\begin{array}{l}\text { Mean } \\
\text { Square }\end{array}$ & $F$ & Sig. \\
\hline 1 sion & & & & & $\begin{array}{r}26 . \\
936\end{array}$ & $\begin{array}{r}.00 \\
0^{\mathrm{b}}\end{array}$ \\
\hline & & 20.968 & 54 & .388 & & \\
\hline & Total & 52.345 & 57 & & & \\
\hline
\end{tabular}

a. Dependent Variable: $Y$

b. Predictors: (Constant), X3, X2, X1

Sumber: Data olahan, 2019

Berdasarkan tabel 3 diatas dapat diketahui bahwa nilai $F_{\text {hitung }}$ adalah sebesar 26,936 dengan taraf signifikan sebesar 0,000 . Selanjutnya untuk jumlah sampel sebanyak 58 sampel dan 3 variabel bebas yang diteliti, maka dapat dikatahui bahwa besarnya nilai $F_{\text {tabel }}$ adalah sebesar 2,78. Karena nilai $F_{\text {hitung }}>F_{\text {tabel }}$ yaitu 26,936 $>2,78$ dan memiliki taraf signifikansi sebesar 0,000 yang lebih kecil dari 0,05, maka Ho ditolak dan Hi diterima. Dengan demikian dapat disimpulkan bahwa pencatatan $\left(X_{1}\right)$, inventarisasi $\left(X_{2}\right)$, dan pelaporan $\left(\mathrm{X}_{3}\right)$ secara bersama-sama atau simultan berpengaruh signifikan terhadap penatausahaan asset tetap pada Kantor Dinas Olahraga dan Pemuda Provinsi Papua. 


\section{Pembahasan}

Pengaruh Pencatatan Terhadap Penatausahaan Asset Tetap Pada Kantor Dinas Olahraga Dan Pemuda Provinsi Papua

Berdasarkan hasil penelitian dan pengolahan data yang dilakukan menunjukkan bahwa pencatatan mempunyai pengaruh yang signifikan secara parsial terhadap penatausahaan asset tetap pada Kantor Dinas Olahraga dan Pemuda Provinsi Papua. Hal ini berarti Penulisan asset tetap pada Kantor Dinas Olahraga dan Pemuda Provinsi Papua sudah dilakukan dengan baik, Penghitungan jumlah asset tetap sudah tepat, semua aset tetap sudah diberikan pengkodean, pemilihan asset tetap rutin dilakukan setiap tahunnya, dan pemindahan aset tetap yang dimiliki oleh Kantor Dinas Olahraga dan Pemuda Provinsi Papua selalu dilakukan pencatatan.

Sejalan dengan penelitian terdahulu yang dilakukan oleh Evita Daufty (2015) dengan hasil penelitian yang menunjukkan bahwa sistem dan prosedur penatausahaan sudah sesuai dengan ketentuan/peraturan yang berlaku. Prosedur atau tahapan pembukuan menurut Peraturan Menteri Dalam Negeri Nomor 17 Tahun 2007 antara lain:

a) Pengguna/kuasa pengguna barang wajib melakukan pendaftaran dan pencatatan barang milik daerah ke dalam Daftar Barang Pengguna (DBP) dan Daftar Barang Kuasa Pengguna (DBKP).

b) Pengguna/kuasa pengguna barang dalam melakukan pendaftaran dan pencatatan sesuai dengan format yang telah ditentukan yaitu format Kartu Inventaris Barang A, B, C, D, E dan F.

c) Pembantu pengelola melakukan koordinasi dalam pencatatan dan pendaftaran barang milik daerah ke dalam Daftar Barang Milik Daerah (DBMD).

\section{Pengaruh Inventarisasi Terhadap Penatausahaan Asset Tetap Pada Kantor Dinas Olahraga Dan Pemuda Provinsi Papua}

Inventarisasi merupakan kegiatan untuk menyediakan data atas semua logistik yang dimiliki/dikuasai/diurus organisasi, baik sebagai hasil usaha pembuatan sendiri, pembelian, 
pertukaran, hadiah, maupun hibah, baik berkaitan dengan jenis dan spesifikasinya, jumlah, sumber, waktu pengadaan, harga, tempat, dan kondisi, serta perubahan-perubahan yang terjadi guna mendukung proses pengendalian dan pengawasan logistik, serta mendukung efektivitas dan efisiensi dalam upaya pencapaian tujuan organisasi (Hilman, 2019). Inventarisasi yang baik mampu menyediakan informasi berkaitan dengan keberadaan barang. Informasi tersebut dapat digunakan sebagai sarana untuk melakukan pengawasan dan pengendalian barang serta dapat digunakan sebagai instrumen pengambilan keputusan berkaitan dengan tindakan-tindakan manajemen barang, seperti pengadaan barang, distribusi, dan penghapusan barang.

Berdasarkan hasil penelitian dan pengolahan data yang dilakukan menunjukkan bahwa inventarisasi mempunyai pengaruh yang signifikan secara parsial terhadap penatausahaan asset tetap pada Kantor Dinas Olahraga dan Pemuda Provinsi Papua. Hal berarti jumlah aset tetap pada Kantor Dinas Olahraga dan Pemuda Provinsi Papua sudah tepat, sumber-sumber aset tetap semuanya sudah jelas, waktu pengadaan aset tetap semuanya sudah jelas, harga semuanya aset tetap sudah tepat, dan Kondisi aset tetap pada Kantor Dinas Olahraga dan Pemuda Provinsi Papua semuanya baik.

Sejalan dengan penelitian terdahulu yang dilakukan oleh Supit, Tinangon, \& Mawikere (2017) dengan hasil penelitian menunjukkan bahwa Inventarisasi barang milik daerah sudah dilakukan dengan benar yang dilaksanakan bersama dengan kegiatan sensus barang/aset.

\section{Pengaruh Pelaporan Terhadap Penatausahaan Asset Tetap Pada Kantor Dinas Olahraga Dan Pemuda Provinsi Papua}

Laporan merupakan sesuatu yang berhubungan dengan menunjukkan kondisi sebuah organisasi. Laporan dibuat untuk mempertanggungjawabkan manajemen sebuah organisasi. Tujuan dilakukan pelaporan adalah untuk menyediakan informasi mengenai asset tetap yang ada pada sebuah organisasi. 
Berdasarkan hasil penelitian dan pengolahan data yang dilakukan menunjukkan bahwa pelaporan mempunyai pengaruh yang signifikan secara parsial terhadap penatausahaan aset tetap pada Kantor Dinas Olahraga dan Pemuda Provinsi Papua. Hal ini berarti bahwa penyusunan laporan aset tetap pada Kantor Dinas Olahraga dan Pemuda Provinsi Papua sudah baik dan jelas, laporan aset tetap bisa dilihat untuk masyarakat umum yang memerlukan data tentang aset tetap yang ada pada Kantor Dinas Olahraga dan Pemuda Provinsi Papua, pegawai selalu konservatif dalam menjaga aset tetap yang ada pada kantor, taksiran harga aset tetap sudah sesuai, dan pegawai pada Kantor Dinas Olahraga dan Pemuda Provinsi Papua sudah merasa tepat dengan pengadaan atau aset tetap yang ada.

\section{Pengaruh Pencatatan, Inventarisasi, Dan Pelaporan Secara Simultan Terhadap} Penatausahaan Asset Tetap Pada Kantor Dinas Olahraga Dan Pemuda Provinsi Papua

Penatausahaan asset merupakan kumpulan dari beberapa bagian yang memiliki keterkaitan dan saling bekerja sama serta membentuk suatu kesatuan untuk mencapai suatu tujuan pada sebuah organisasi. Penatausahaan asset dimaksudkan yaitu untuk mencapai suatu tujuan dan sasaran dalam ruang lingkup yang sempit.

Berdasarkan hasil penelitian dan pengolahan data yang dilakukan menunjukkan bahwa bahwa pencatatan, inventarisasi, dan pelaporan secara bersama-sama atau simultan berpengaruh signifikan terhadap penatausahaan asset tetap pada Kantor Dinas Olahraga dan Pemuda Provinsi Papua. Hal ini menunjukkan bahwa aset tetap yang ada pada Kantor Dinas Olahraga dan Pemuda Provinsi Papua semuanya jelas dan terarah, pelaksanaan penatausahaan aset tetap sudah dilakukan secara rutin, penerimaan aset tetap semuanya jelas dan sesuai dengan mekanisme yang berlaku, pengeluaran aset tetap sudah sesuai dengan kebutuhan yang ada, dan Pengarsipan aset tetap pada Kantor Dinas Olahraga dan Pemuda Provinsi Papua selalu dilakukan dan berjalan dengan baik.

Berbanding terbalik penelitian yang dilakukan oleh Kurniati, Asmony, \& Santoso (2017) dengan hasil penelitian menunjukkan bahwa kegiatan penatausahaan aset tetap yang 
di lakukan di pemerintah masih mengalami kendala diantaranya kurangnya tenaga dan kualitas pengelola aset dan koordinasi antara pengurus barang dan bendahara pengeluaran yang belum berjalan dengan baik.

\section{Faktor Yang Paling Dominan Berpengaruh Terhadap Terhadap Penatausahaan Asset}

\section{Tetap Pada Kantor Dinas Olahraga Dan Pemuda Provinsi Papua}

Pembukuan merupakan pencatatan barang yang digunakan pada pengguna barang, agar barang yang digunakan tercatat dengan baik. Menurut Permendagri No. 19 Tahun 2016 yang dimaksud dengan pembukuan adalah proses pencatatan barang milik daerah ke dalam daftar barang pengguna dan ke dalam kartu inventarisasi barang serta dalam daftar barang milik daerah, kegiatan yang dilakukan seperti:

a. Pengguna/kuasa pengguna barang wajib melakukan pendaftaran dan pencatatan barang milik daerah ke dalam daftar barang pengguna (DBP)/daftar barang kuasa pengguna (DBKP).

b. Pengguna/kuasa pengguna barang dalam melakukan dan pencatatan sesuai format:

1. Kartu Inventaris Barang (KIB) A Tanah

2. Kartu Inventarisasi Barang (KIB) B Peralatan dan Mesin

3. Kartu Inventarisasi barang (KIB) C Gedung dan Bangunan

4. Kartu Inventarisasi barang (KIB) D Jalan, Irigasi dan jaringan

5. Kartu Inventarisasi Barang (KIB) Aset Tetap lainnya

6. Kartu Inventarisasi Barang (KIB) F Konstruksi dalam Pengerjaan

7. Kartu Inventarisasi Ruangan (KIR)

Berdasarkan hasil pengolahan data yang dilakukan menunjukkan bahwa variabel yang paling dominan berpengaruh terhadap penatausahaan asset tetap pada Kantor Dinas Olahraga dan Pemuda Provinsi Papua adalah variabel pencatatan. Pemerintah harus mencatat suatu aset tetap yang dimilikinya meskipun aset tetap tersebut digunakan oleh pihak lain. Pemerintah juga harus mencatat ha katas tanah sebagai aset tetap. Dalam kasus 
lain, aset tetap yang dikuasai oleh pemerintah tetapi tujuan penggunaannya untuk dikonsumsi dalam operasi pemerintah tidak termasuk dalam aset tetap.

\section{KESIMPULAN}

Berdasarkan pembahasan hasil penelitian, maka kesimpulan yang dapat disampaikan melalui penelitian ini adalah sebagai berikut:

1. Pencatatan, Inventarisasi, dan Pelaporan secara parsial berpengaruh positif dan signifikan terhadap penatausahaan aset tetap pada Kantor Dinas Olahraga dan Pemuda Provinsi Papua.

2. Pencatatan, Inventarisasi, dan Pelaporan secara simultan berpengaruh positif dan signifikan terhadap penatausahaan aset tetap pada Kantor Dinas Olahraga dan Pemuda Provinsi Papua.

3. Pencatatan merupakan faktor yang dominan berpengaruh signifikan terhadap penatausahaan aset tetap pada Kantor Dinas Olahraga dan Pemuda Provinsi Papua.

\section{DAFTAR PUSTAKA}

Agustin, M. (2018). Administrasi Sewa Terhadap Barang Milik Negara Pada Kantor Pelayanan Kekayaan Negara Dan Lelang (KPKNL) Jember. Retrieved from http://repository.unej.ac.id/handle/123456789/88263

Arikunto, S., \& Jabar, A. (2010). Evaluasi Program Pendidikan, Pedoman Teoretis Praktis Bagi Praktisi Pendidikan (Vol. 2).

Hilman, A. (2019). Pengaruh Inventarisasi Aset, Penilaian Aset Dan Legal Audit Terhadap Kualitas Laporan Keuangan Pemerintah Kota Tasikmalaya (Survei Pada Satuan Kerja Perangkat Daerah Kota Tasikmalaya). Universitas Siliwangi.

Kurniati, E., Asmony, T., \& Santoso, B. (2017). Kemelut Penatausahaan Aset Tetap (Dulu Hingga Kini). Jurnal Akuntansi Multiparadigma, 8(3), 540-558.

Makagansa, E. D. M. (2015). Evaluasi Sistem dan Prosedur Akuntansi Aset tetap pada Dinas Pendidikan Pemuda dan Olahraga Kabupaten Kepulauan Sangihe. EFISIENSI, 15(5).

Permendagri No. 19 Tahun. tentang Pedoman Pengelolaan Barang Milik Daerah. , (2016).

Sholeh, C., \& Rochmansjah, H. (2010). Pengelolaan Keuangan dan Aset Daerah Sebuah Pendekatan Struktural Menuju Tata Kelola Pemerintahan Yang Baik. Bandung: Fokusmedia. 
Supit, P. T., Tinangon, J. J., \& Mawikere, L. M. (2017). Evaluasi Penatausahaan Barang Milik Daerah Menurut PP No. 27 Tahun 2014 pada Badan Pengelola Keuangan dan Aset Daerah Kota Manado. GOING CONCERN: JURNAL RISET AKUNTANSI, 12(2).

Wulandari, E. O. (2019). Administration Tata Usaha. 